\title{
A Longa Duração, A Grande Divergência e A Grande Convergência: sumários apontamentos acerca da influência de Fernand Braudel na compreensão do atual sistema econômico mundial
}

The Long Duration, The Great Divergence and The Great Convergence: brief comments about the Braudel's influence on the comprehension of the current world economic system

\author{
Carlos Leonardo Kelmer Mathias*
}

\begin{abstract}
Resumo
O presente artigo tem por escopo identificar aspectos do pensamento braudeliano na historiografia acerca do sistema econômico mundial e pontuar seus ecos nos estudos sobre a chamada "Great Divergence". Em essência, trata-se de um conjunto de historiadores que compreende a formação do moderno sistema econômico em uma perspectiva concomitantemente mundial e estrutural. Há alguns anos, a chamada "escola da Califórnia" vem desenvolvendo seus estudos com base na verticalização analítica do fenômeno denominado the "Great Divergence", isto é, o processo iniciado no albor do século XIX que, por um lado, redundou em um contínuo afastamento no nível de desenvolvimento econômico da Europa - notadamente da Inglaterra - e por outro, da China, após séculos de liderança do país asiático. Parte dessa orientação de pesquisa está calcada no vertiginoso processo de crescimento econômico experimentado não apenas pela China a partir da década de 1980, mas também por outras potências emergentes, dentre as quais o Brasil. Semelhante movimento foi denominado the "Great Convergence" pela historiografia que dialoga com a "escola da Califórnia". A influência braudeliana é passível de ser observada não apenas na inclinação à longa duração, mas também no fato de o autor ter sido um dos pioneiros a constatar a importância chinesa na constituição da economia mundial já no século XVI.
\end{abstract}

Palavras-chave: Braudel; longa duração; sistema econômico mundial.

\begin{abstract}
The present article intents to identify some aspects of the Braudel's thought in the historiography that studies the world economic system. It also points out how Fernand Braudel influenced that researches about the "Great Divergence". Indeed, it is about a pool of historians that understand the formation of the modern economic system in a global and structural perspective. During these last years, the "California School" has been a base of study of the vertical analyse of the phenomenon of the "Great Divergence". This process started in early nineteen century and resulted in a continuum gap between Europe and China in terms of economic development after centuries of Chinese leadership. One of the reasons for the begin of this kind of research is related to the Chinese vigorous economic growth since 1980's, besides the development of others emerging nations, such as Brazil. This global movement was denominated as the "Great Convergence" by the historiography which dialogues with the Californian School. It is possible to see the Braudel's influence not only in terms of the long duration, but also in the fact that Braudel was one of the pioneers to detect the Chinese importance in the constitution of the world economy in the XVI century.
\end{abstract}

Keywords: Braudel; long duration; world economic system.

\footnotetext{
* Doutor em História Social pela Universidade Federal do Rio de Janeiro (UFRJ). Professor adjunto da Universidade Federal Rural do Rio de Janeiro (UFFRJ).
}

Recebido em novembro de 2017 | Aprovado em abril de 2018. 


\section{Introdução}

Em novembro de 2001, Jim O`Neill, então um dos principais economistas do grupo financeiro Goldman Sachs, endereçou um relatório para os clientes da instituição no qual destacava as potencialidades de crescimento e as oportunidades de investimento, apresentadas pelo acrônimo BRICS - grupo composto por Brasil, Rússia, Índia, China e, desde abril de 2011, pela África do Sul. As principais teses do documento informavam: a) o crescimento real do Produto Interno Bruto dos mercados emergentes excederia aos apresentados pelo G7 - grupo composto por Alemanha, Canadá, Estados Unidos, França, Itália, Japão e Reino Unido; b) no final de 2000, em termos de paridade de poder de compra medido em dólar, Brasil, Rússia, Índia e China responderam por aproximadamente $23,3 \%$ do PIB mundial sendo que, no decurso de 2001, esses quatro países respondiam por $8 \%$ do PIB mundial; c) o PIB chinês já era maior do que o italiano; d) nos próximo dez anos, o peso dos BRICS no PIB mundial (principalmente no que concerne à participação chinesa) crescerá, majorando a relevância de temas sobre o impacto econômico global das políticas fiscais e monetárias dos BRICS; e) em diapasão com esses prospectos, os fóruns de formulação política globais deverão ser reorganizados, em particular o G7, de modo a incorporar os representantes dos BRICS (O`NEILL, 2001).

Em que pese a expressividade dos demais membros, indubitavelmente, a China é o país de maior envergadura e importância no seio do grupo tanto em termos geopolíticos quanto em âmbito econômico. A título de exemplo, Brasil, Rússia, Índia, China e África do Sul reportaram os seguintes PIBs em 2016: US\$ 1,796 trilhão, US\$ 1,283 trilhão, US\$ 2,264 trilhões, US\$ 11,2 trilhões e US\$ 294,8 bilhões, respectivamente. Consoante a tabela 1, a China, globalmente, é o país que entrega o maior crescimento econômico desde 1981. Semelhantes números alçam a econômica chinesa ao patamar de segunda maior no mundo atrás, somente, dos Estados Unidos da América. Em março de 2013, o grupo criou, na cidade sul-africana de Durban, o Novo Banco de Desenvolvimento, comumente denominado Banco dos BRICS, cuja sede está localizada em Xangai. A referida instituição encerra uma distinta alternativa ao Fundo Monetário Internacional e ao Banco Mundial, entidades erigidas, via acordo de Bretton Woods na esteira da $2^{a}$ Guerra Mundial, em 1944. ${ }^{1}$ Na medida em que não vem a pelo discorrer sobre a história econômica dos países componentes dos BRICS, no geral, ou

\footnotetext{
${ }^{1}$ A literatura acerca do tema é ampla e diversificada. Para uma consulta de referência, conferir Visentini, 2013 e Hurrell, 2009.
} 
da China, em particular, pois importa registrar é que o gigante asiático convalida seu crescimento econômico na reiteração temporal de seu PIB a taxa média de 9,71\% ao ano entre 1981 e 2016, ante 2,68\% dos EUA e, principalmente, 2,26\% do Reino Unido. ${ }^{2}$

\section{Tabela 1 - Crescimento médio do PIB dos BRICS, e dos principais países do G7, 1981-2016}

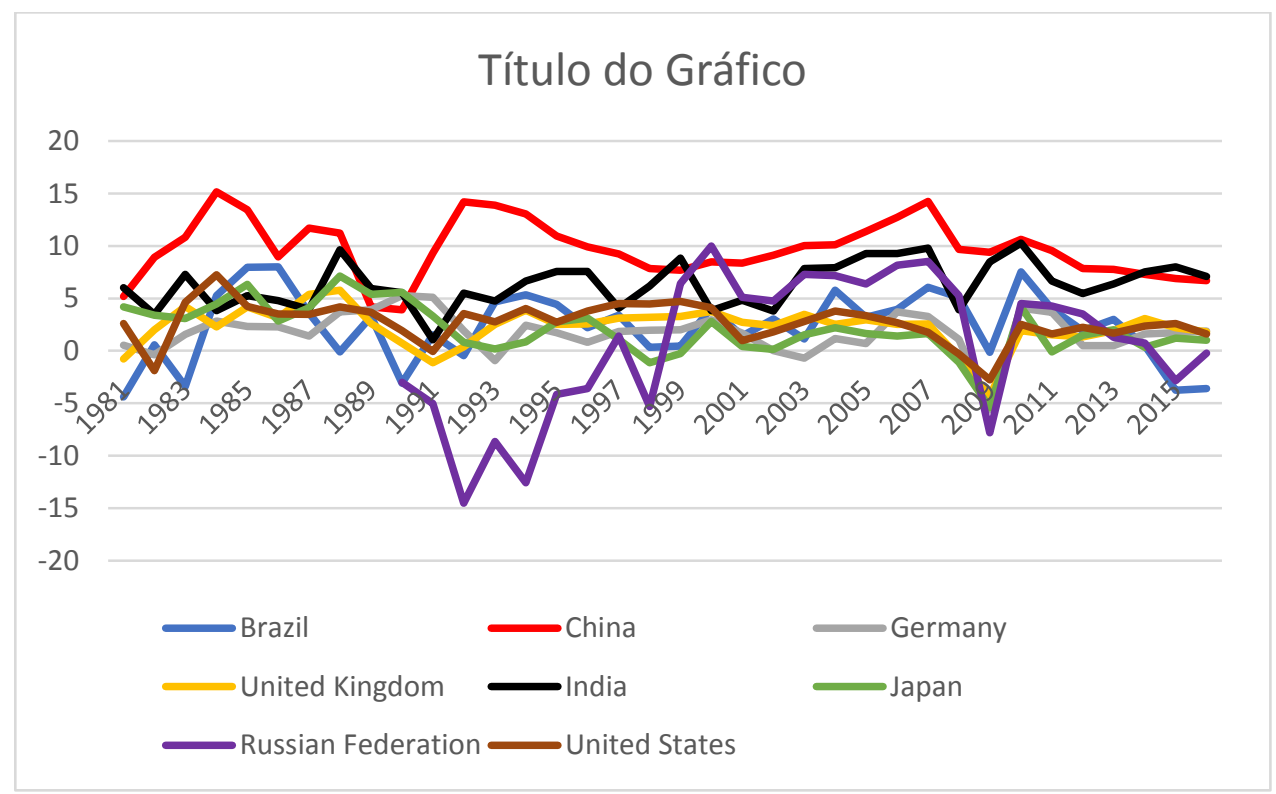

Fonte: http://www.imf.org/external/index.htm.

À vista disso, a partir de finais da década de 1990, um grupo de pesquisadores liderados por Jack Goldstone e, posteriormente, inspirados pela seminal obra de Kenneth Pomeranz (2000), envidou esforços no sentido de compreender a natureza do processo histórico de desenvolvimento chinês, cujo resultado alçou o referido país à condição atual de segunda maior economia do mundo. O ponto em tela consiste, precisamente, em sublinhar o método elegido para tanto. Direta ou indiretamente e ao abrigo das diversas orientações históricas, sociológicas e econômicas, o recorte temporal da longa duração pautou tais análises. Invariavelmente, os estudiosos do tema adotam cronologia secular, de "respiração mais contida", nas palavras de Fernand Braudel (2005, p. 44), com o fito de matizar suas lentas transformações, aquelas observáveis apenas na longuíssima duração. Não deve causar espécie, pois, que, consoante Leonid Grinin e Andrey Korotayev (2015), o albor da Grande Divergência,

\footnotetext{
${ }^{2}$ Fonte: http://www.imf.org/external/index.htm. O destaque para o Reino Unido se impõe na medida em que a Grande Divergência é recorrentemente estudada a partir do cotejamento entre tal região e a China.
} 
cujo zênite foi alcançado no início do século XIX com o advento da Revolução Industrial inglesa, deva ser buscado por volta do século XI. Por outro lado, todas as transformações estruturais que viabilizaram esse grande gap entre China e Inglaterra foram as mesmas responsáveis pela pavimentação do caminho conducente à Grande Convergência, passível de ser aferida a contar do princípio da década de 1980. A isto, voltarei.

\section{Sucintos apontamentos acerca da Longa Duração e do aporte de Braudel para a história chinesa}

Em 1942, Marc Bloch postulou que a atmosfera em que o pensamento do historiador respira é a categoria da duração, o tempo. Na mesma obra e poucas páginas a diante, empreendeu o apontamento a seguir no tocante ao métier de muitos economistas às voltas com o estudo da economia coeva. Em suas palavras, o problema repousa no fato segundo o qual esses pesquisadores "pretendem compreender a economia contemporânea com a ajuda de observações limitadas, no tempo, a algumas décadas". Logo, "consideram a época em que vivem como separada das que o precederam por contrastes vivos demais para trazer em si mesma sua própria explicação". O óbice repousa na dificuldade em superar a tentação de abandonar a complexidade do processo histórico explicativo das sociedades atuais face à sedução simplificadora daquilo que vige diante do olhar afoito. Com meridiana clareza, Bloch vaticinou o caminho epistemológico da longa duração ao pôr, em relevo, a necessária dialética temporal entre passado e presente como ferramenta heurística de investigação histórica: “a incompreensão do presente nasce fatalmente da ignorância do passado. Mas talvez não seja menos vão esgotar-se em compreender o passado se nada se sabe do presente" (BLOCH, 2001, p. 55-65).

Ao abrigo do precedente, não podemos tomar por fortuito a consideração de Braudel de que "a história é uma dialética da duração: por ela, graças a ela, é estudo do social, de todo o social, e, portanto, do passado, e, portanto, também do presente, um e outro inseparáveis”. Tal pêndulo temporal pauta-se pela gradação clivada em três níveis. O primeiro é o da superfície, ou seja, de "uma história factual" que "se inscreve no tempo curto: é uma micro história". A seguir, a chamada "história conjuntural", com seu "ritmo mais largo e mais lento" até, por fim, adentrarmos à história estrutural ou de longa duração, responsável por conjugar séculos, flertando nos limites entre o "móvel e 
o imóvel". Em detalhe, a longa duração seria o espaço privilegiado para o estudo das estruturas mais persistentes da história das civilizações, pois tais arquétipos temporais são passíveis de transcorrerem por recortes cronológicos longevos sem consideráveis alterações em suas morfologias. Assim posto, a análise da longa duração provê o mais adequado meio "para uma observação e uma reflexão comuns às ciências sociais" (BRAUDEL, 2005, p. 75-106) - colocação deveras providencial, diga-se de passagem, haja vista que os estudos acerca da Grande Divergência e subsequente Convergência, são levados a cabo por historiadores, cientistas sociais e economistas, no geral.

Estabelecido o anterior, depreende-se o raio trator que a longa duração exerceu, e exerce, sobre os estudiosos do tema ora em tela. A exata medida da interdisciplinaridade necessária à empresa demanda um recorte cronológico apto a conjugar passado e presente com vistas à compreensão das lentas, mas profundas, mudanças vivenciadas pelas sociedades chinesa e inglesa. Precisamente nesse ponto é que repousa a validade da proposta. Dado o cariz quase imóvel das mudanças, uma transformação por demais representativa dificilmente escaparia ao olhar do pesquisador. Do posto, os próprios estudos de Braudel (1987) acabaram por englobar a história chinesa.

A título de exemplo, orientando sua atenção para a história do desenvolvimento do sistema capitalista mercantil, o autor (1987, p. 21-24) tratou de empreender uma comparação entre características estruturais europeias e asiáticas. Dessa forma, questionou-se se os mecanismos de troca observáveis na Europa setecentistas - tais como: bolsas de valores, letras de câmbio, sistema bancário relativamente integrado, políticas cambiais, etc -, outrossim, o são para regiões como China, Índia, Islã ou Japão. O escopo consiste em verificar "se o crescente abismo que vai cavar-se entre essas regiões já era visível antes da Revolução Industrial, antecipando-se em relação ao resto do mundo". No geral, concluiu que, ao arrostarmos as economias do resto do mundo com a europeia, as causas basilares do avanço europeu repousariam na existência e no aprimoramento de seus instrumentos e instituições, tais como as bolsas de valores e as diversas formas de crédito. Particularmente, no caso chinês, a explicação braudeliana para o não florescimento do capitalismo por aquelas paragens repousou, basicamente, na ingerência estatal sobre variados aspectos da vida econômica. Nos seus termos:

O Estado chinês, apesar das cumplicidades locais de mercadores e de mandarins corruptos, foi permanentemente hostil ao florescimento de um capitalismo que, toda vez que cresce ao sabor das circunstâncias, é, em última instância, devolvido à ordem por um Estado de certo modo totalitário 
(estando a palavra despida de seu atual sentido pejorativo). Só existe verdadeiro capitalismo chinês fora da China - na Insulíndia, por exemplo, onde o mercador chinês age e reina com toda a liberdade (BRAUDEL, 1987, p. 49).

Não vem a pelo discorrermos sobre a pertinência ou não de suas explicações acerca dos óbices pelo autor avocados como impedimentos para o albor do sistema capitalista chinês pari passu ao europeu. Aqui, faz-se mais imperioso pontuarmos exemplos do alcance de suas considerações na historiografia atinente ao tema. Conforme Peer Vries (2015, p. 379), as políticas perpetradas pela dinastia Qing (16441912) controlavam o comércio com o ocidente, restringindo-o a certos espaços específicos e desestimulando os mercadores chineses a participarem ativamente das empresas comerciais externas - isso quando não os impediam formalmente. O corolário consistiu na inexistência tanto de uma rede comercial global quanto da expertise daí advinda. Tendo em conta que a China adotou o sistema monetário argênteo, tal cenário facilitou a emersão de uma estrutural comercial consideravelmente ávida pela prata. Dessa forma, o fato de o metal ter sido a mercadoria mais importada pela China fez de seu sistema monetário (financeiro e creditício) extremamente refém desse processo estrutural de importação. Pautando, Vries verticaliza, a rigor, os dois pontos elegidos por Braudel como fatores explicativos para o não desenvolvimento do sistema capitalista na China, a saber: o cariz excessivamente interveniente do Estado, em particular, e a atrofia do seu sistema de troca em âmbito externo, no geral.

Uma das principais características da historiografia interessada em compreender o sistema econômico mundial após a Segunda Guerra Mundial teve por fito investigar dois pontos, quais sejam: a estratégia de acumulação/transferência de riqueza em escala global e a participação do ultramar nesse processo. Buscava-se explicações e proposições para a superação da pobreza pelos países então classificados como de Terceiro Mundo (VRIES, 1991, p. 275-276). Desse empreendimento, veio à luz uma variada gama de trabalhos de matriz histórica, sociológica e econômica. No que me importa mais de perto, buscarei, modestamente, expor aquilo que considero o principal aporte de Braudel para o tema: sua leitura acerca dos mecanismos de acumulação na longa duração, enfatizando o caráter submisso da periferia frente ao centro. ${ }^{3}$ Em

\footnotetext{
${ }^{3}$ A bem dizer, discordo frontalmente das perspectivas que hierarquizam o centro europeu face à periferia mundial na época moderna. Outrossim, urge salientar que, em momento algum do corrente artigo, estou a convalidar as análises que identificam a lógica econômica das sociedades pré-industriais como capitalista. Aqui, trato tão somente de intentar identificar a influência de Braudel nos estudos do sistema econômico
} 
essência, para autor (1995, 1996a e 1996b), o desenvolvimento histórico do capitalismo imerso nas esferas da circulação, da produção e da finança foi matizado pela coexistência de três camadas econômicas: a da vida cotidiana, a do mercado e a do capitalismo que, de diversas formas e em diversas escalas, podem ser identificadas desde pelo menos o século XII. Dentre os três níveis em tela, o terceiro promove, via comércio de longa distância, circuito monopolístico e privilégio de informação, os vultosos lucros imperativos à implantação do estágio final de maturação do sistema capitalista no albor da Revolução Industrial. Tratar-se-ia de um processo de acumulação de longa duração e, com o devir, em escala mundial. Dentre as componentes desse processo, as demais regiões alheias à Europa que teriam, a rigor, atuado como espaços periféricos.

Um dos autores mais fortemente influenciados pela proposta braudeliana foi Immanuel Wallerstein (2010a, 2010b, 2010c). Admitindo as transformações pelas quais os Estados passaram como resultante do caráter evolutivo e interacional do sistema mundial, o autor tomou por balizas temporais os séculos XVI e XIX. Passou, pois, ao estudo dos primórdios da divisão internacional do trabalho e do papel do Estado nos mesmos. Em boa verdade, a cronologia em questão dialoga estreitamente não apenas com a Longa Duração, mas fundamentalmente com o período no qual as alterações estruturais europeias e chinesas engendraram A Grande Divergência. Seja como for, Wallerstein se debruçou sobre a teorização da, então denominada, "economia-mundo". Com o florescimento inicial entre finais do século XV e início do seguinte, a economiamundo europeia, embora não denotasse um Império, possuía vastidão territorial e configuração econômica semelhantes - malgrado o mesmo não possa ser afirmado no que respeita à centralização política própria dos impérios e das Cidades-Estados. Seu verniz mundial respondia ao fato de o vínculo entre as partes do sistema ser de natureza econômica, ou seja, a própria força motriz das relações mercantis fomentava o avanço físico desse conjunto como um todo - naturalmente, vez por outra, certos arranjos políticos e culturais costuravam esse desenvolvimento.

Com o nascimento do século XVI, a economia-mundo avocou sua faceta capitalista, majorada na apropriação de um excedente baseado em uma produtividade agrícola, posteriormente industrial, mais eficiente e ampliada via mecanismos de um mercado mundial com assistência do Estado, então, adstrito aos interesses econômicos

mundial e nas discussões atinentes à Grande Divergência. Para o meu posicionamento na discussão anterior, conferir Kelmer Mathias (2017). 
consubstanciados em um projeto de poder. Para tanto, fez-se imperativo a expansão do volume geográfico do mundo, o desenvolvimento de efetivos métodos de controle do trabalho consoante as diferentes partes constituintes da economia-mundo capitalista e, por fim, a ereção de aparatos estatais fortes no centro dessa economia capazes de salvaguardarem a apropriação do sobretrabalho e a consequente transferência de riqueza para a Europa. Face à natureza do Estado chinês, sua organização político-econômica não estava apta a configurar uma economia-mundo capitalista, mas sim um Império ${ }^{4}$ donde parte da influência braudeliana pode ser atestada no pensamento de Wallerstein. ${ }^{5}$

No que toca à Ásia com um todo, Wallerstein (2010a, p. 464-469) colige como um dos principais fatores de exclusão de sua participação na economia-mundo europeia o fato de que, desde o século XVI até o XVII, as relações mercantis e políticas entre as partes respondiam aos termos estabelecidos pelos asiáticos e não pelos europeus. Em adição, o autor releva dois outros pontos, a saber: a) o comércio com a Ásia não formatou alterações na estrutura política e social dos asiáticos e b) a produção primária da Ásia não tomava parte na divisão europeia do trabalho. Resulta, claramente, os pontos em contato entre Wallerstein e Braudel. Mesmo desconsiderando que ambos trabalham com a perspectiva de economia-mundo, a premissa wallersteriana é caudatária da expansão, via comércio de longa distância, dos superlucros auferidos por intermédio do capitalismo monopolista braudeliano. Em tempo, não convém desconsiderar que tanto a própria escala temporal de observação quanto o fato de que, para Braudel, e aqui me expresso laconicamente, dois dos principais impedimentos da ascensão do sistema capitalista na China deitam raízes nas naturezas de seu Estado e de seu sistema de troca. Tais características foram absorvidas por Wallerstein, a primeira mais do que a segunda, quando o mesmo discorre acerca das razões de o Estado chinês

\footnotetext{
${ }^{4}$ Para uma crítica acerca desse ponto específico do pensamento de Wallerstein, conferir Vries (2015, p. 392-407).

${ }^{5}$ A confluência de pensamento entre ambos os autores, outrossim, é passível de ser atestada na própria definição de Braudel (1987, p. 54-60) sobre economia-mundo. A bem dizer, o próprio Braudel ressalta as semelhanças: "pouco importa que eu não esteja sempre de acordo com o autor (Wallerstein) sobre tal ou tal ponto, até mesmo sobre uma ou duas linhas gerais. Os nossos pontos de vista, quanto ao essencial, são idênticos". De acordo com Braudel, sua definição de economia-mundo passa por três fatores, quais sejam: a) estar inserida em um espaço geográfico dado, podendo ser alterado de tempos em tempos, b) possuir sempre um centro, sendo este uma ou duas cidades/capitais e c) ser composta por "zonas sucessivas", ou seja, afora o centro, haver zonas intermediárias e zonas marginais. Em resumo, a economia-mundo europeia, em 1650, é a "justaposição, a coexistência de sociedades que vão desde a sociedade já capitalista, a holandesa, até as sociedades servis e escravistas, no fundo da escala (...). Como há reciprocidade das perspectivas, se o centro depende dos abastecimentos provenientes da periferia, esta depende, por sua vez, das necessidades do centro que lhe dita sua lei”.
} 
ter se desenvolvido nos moldes de um Império e não de uma economia-mundo capitalista.

$\mathrm{Na}$ medida em que um dos escopos do corrente artigo consiste em pontuar, superficialmente, a influência de Braudel nos estudos sobre o sistema econômico mundial na época moderna e seu desdobramento nas pesquisas sobre A Grande Divergência, não podemos prescindir de abordarmos Giovanni Arrighi (1999 e 2013). Compartilhando da premissa braudeliana de que o capital encerra resiliência e maleabilidade a nível irresistível, Arrighi empreendeu um estudo de Longa Duração orientado para captar os ritmos estruturais de mudança cíclica no processo histórico da formação do sistema capitalista. Nesse sentido, seus interesses se associam com os de Wallerstein e com os do próprio Braudel. O principal instrumento analítico é o conceito de "ciclo sistêmico de acumulação", ou seja, recortes de Longa Duração pautados por ascensão e queda tanto de potências hegemônicas a nível mundial quanto de seus respectivos modelos de acumulação (precisamente Gênova, Holanda, Grã-Bretanha e Estados Unidos, nessa ordem - importante notar a ausência da China, principalmente entre o período composto pelas dinastias Song e Qing). ${ }^{6}$

Creio não ser demasiadamente arriscado empreender um cotejamento entre a hierarquia política do sistema de Arrighi com a compreensão de Braudel acerca da constituição do capitalismo em si. Para o primeiro, em cada ciclo do desenvolvimento histórico do capitalismo, o Estado hegemônico seria composto por forças capitalistas particulares como, por exemplo, companhias comerciais monopolísticas. Em diapasão, essas duas esferas responderiam pelo exercício de poder e pelo controle dos processos estruturais de acumulação de capital no sistema econômico mundial. Em termos comparativos, as considerações, que sobre o tema têm lugar, dizem respeito ao fato de que, para Braudel, o campo privilegiado de acumulação e de desenvolvimento do sistema capitalista é do comércio de longa distância, monopolizado e altamente concentrado, observado na Longa Duração. Afora a concatenação entre os autores atinente à esfera superior de circulação de capital com vistas à acumulação, talvez seja possível ousar um pouco mais e sugerir que o modelo de Arrighi viabilizaria a identificação, no tempo, das ocorrências e das características das alterações do poder

\footnotetext{
${ }^{6}$ Consoante Arrighi, "a ideia braudeliana das expansões financeiras como fases finais dos grandes desenvolvimentos capitalistas me permitiu decompor a duração completa do sistema capitalista mundial (a longue durée de Braudel) em unidades de análise mais manejáveis, que chamei de ciclos sistêmicos de acumulação" (ARRIGHI, 2013, p. XI). Para trabalhos mais recentes do autor conferir ARRIGHI, 2008; VIEIRA, FILOMENO, VIEIRA, 2012.
} 
político hegemônico face ao caráter quase imóvel das lentas transformações no processo de desenvolvimento do sistema capitalista consoante a proposta temporal braudeliana.

Infelizmente, os textos ora tratados de autoria de Arrighi não avançam para além da década de 1970, o que seria de enorme valia para o refinamento da análise sobre A Grande Convergência. Seja como for e, conforme o cerne da questão que sumariei na introdução do corrente artigo, desde a década de 1980, a economia chinesa vem despontando como a mais dinâmica, em voga, no sistema econômico mundial. A China soube se valer do vazio aberto pela recessão econômica japonesa iniciada na década de 1990 e pela crise dos Tigres Asiáticos, em 1997, e vem liderando, desde então, o padrão Gansos Voadores de crescimento na região da ASEAN. ${ }^{7}$ Vige a questão de se a China será, ou não, capaz de empreender um novo ciclo econômico de acumulação, suprimindo a atual liderança norte-americana em favor da ascensão sina. Não causa espécie, pois, que vários estudiosos estejam voltando seus olhos para o processo histórico de Longa Duração do desenvolvimento econômico desse gigante asiático. Por fim, uma concisa palavra sobre André Gunder Frank (1978).

A concordar com o autor (1978, p. 18 e p. 194), o fator diferencial no desenvolvimento capitalista norte-americano respondeu, por um lado, à anatomia de sua inserção no processo de acumulação mundial de capital como área semiperiférica submissa à economia-mundo capitalista de Wallerstein, e, por outro, à sua peculiar posição no comércio triangular constituinte do sistema econômico moderno. A decorrente acumulação imanente a este cenário facultou aos Estados Unidos principiar seu processo de industrialização. Dito de outro modo, essa região ocupou um rol na expansão do sistema capitalista mercantil mundial e no processo de acumulação de capital que lhe viabilizou o papel de submetrópole da Europa Ocidental, categoria essa que nenhuma outra área do globo jamais ocupou e, por conseguinte, pôde trilhar o caminho que culminou em sua alavancagem como primeira potência mundial no decurso do século XX. Tal fato não teria se passado com a Ásia.

Interessante observar que Gunder Frank (1978, p. 38 e p. 148-150) advoga no sentido de a população asiática ter sido poupada das mazelas inerentes aos processos de formação do capitalismo mercantil mundial e da acumulação de capital europeia até o século XVIII, devido àquela região não ter empregado mão de obra escrava, por um lado, e, por outro, ter atuado como exportadora de produtos manufaturados até o

\footnotetext{
${ }^{7}$ Acerca do tema, conferir Medeiros (2007) e Palma (2007).
} 
surgimento da Revolução Industrial. Com tal advento, a região asiática se transfigurou de importadora à exportadora de capital, favorecendo o capitalismo europeu. Malgrado não esteja tratando sobre o tema, resta patente que o autor toca precisamente no momento de inflexão entre Ásia e Europa, um ponto de viragem estrutural em perspectiva de Longa Duração, que incitou os estudos da Escola da Califórnia à luz dos portentos crescimento e dinamismo da economia chinesa a partir da década de 1980.

\section{A Grande Divergência e A Grande Convergência}

Conforme avançado, o singular comportamento da econômica chinesa nos últimos trinta anos vem seduzindo a atenção de um número cada vez mais expressivo de estudiosos. Em que pese a validade e a necessidade de pesquisas com recortes cronológicos atrofiados como instrumentos explicativos desse comportamento, ultimamente, um número razoável de historiadores, sociólogos e economistas tem se rendido à imprescindibilidade da compreensão histórica do desenvolvimento econômico chinês a partir de uma perspectiva de Longa Duração - quiçá fruto da premissa braudeliana, segundo a qual esse seria o recorte temporal privilegiado da interdisciplinaridade. De todo modo, a obra seminal e inaugural da chamada "Escola da Califórnia" foi o livro de Kenneth Pomeranz, (2000), The Great Divergence. ${ }^{8}$ Para que bem se entenda, não vem a pelo, aqui, discorrer sistematicamente o propósito do livro ou mesmo realizar algo afim a uma resenha. $\mathrm{O}$ mote radica em trabalhar com aspectos que, direta ou indiretamente, podem ser correlacionados com alguns apontamentos braudelianos. Uma vez esclarecidos meus objetivos, passo à execução dos mesmos.

Pomeranz, parti pris, não coaduna com visão deveras eurocêntrica tão cara aos escritos braudelianos. Em tempo, estou a definir por visão eurocêntrica a premente insistência de Braudel em asseverar que o centro do mundo moderno respondia à delimitação geográfica da Europa Ocidental. E, assim, procedeu exclusivamente por considerar apodítica a premissa de que as formas econômicas, políticas, sociais e culturais da região seriam forçosamente mais "avançadas" face às demais regiões componentes do globo. A meu ver, semelhante conduta evoca, conspicuamente, a medida da suposta superioridade do capitalismo (mesmo em seu estágio embrionário) em detrimento das formas "menos sofisticadas" de ordenação macrossocial. Não creio

\footnotetext{
${ }^{8}$ Patrick O`Brien (2010) condensou os principais desdobramentos historiográficos suscitados pelo livro de Pomeranz entre 2000 e 2010.
} 
que comparações, nesse sentido, produzam quaisquer resultados dignos de nota que não a perene reiteração temporal da inferioridade das áreas exógenas à Europa à mesma. Logo, trata-se de uma heteronomia discursiva de poder. Retorno, pois, à Pomeranz.

Para o autor, e no que respeita ao período da época moderna, as diversas conjunturas globais não devem ser tomadas como signo de um sistema mundial centrado na Europa, mas, antes, emblema de "um mundo policêntrico sem um centro dominante". Malgrado tais conjunturas tenham, no geral, favorecido o desenvolvimento europeu, isto não quer dizer que a Europa fosse agente ativa das mesmas, quer criandoas, quer impondo-as. À título de exemplo, embora a remonetização da China por meio da prata a partir do século XV tenha ensejado a viabilidade financeira do Império Espanhol, esse foi um movimento que precedeu a presença europeia na América e, obviamente, o início da produção argêntea em Potosí. Consoante Pomeranz, somente após a industrialização atingir estágio avançado no século XIX faz sentido falarmos "em um único centro europeu hegemônico". Com meridiana clareza, sublinha o autor: "nossa percepção de um sistema interativo no qual uma parte se beneficia mais do que as outras não justifica chamar essa parte de 'centro' e assumir que ela influência o todo e não é influenciada por ele" (POMERANZ, 2010, p. 4-10). Aqui, a prédica caminha em sentido contrário ao braudeliano.

Um dos pontos de maior proficuidade na querela tocante à Grande Divergência se assenta nas alternativas perpetradas pela Europa, notadamente pela Grã-Bretanha, com fito a se desvincular da armadilha malthusiana. ${ }^{9}$ Fundamentalmente, duas foram as soluções: aumento da produtividade do trabalho e a expansão ultramarina. ${ }^{10}$ Interessame, mais de perto, o segundo ponto. À esta altura, julgo escusado advogar em prol da relevância do comércio de longa distância (no qual toma parte o ultramarino) como agente de fomento do desenvolvimento capitalista sob a ótica de Braudel. Simili modo, a natureza do Estado europeu em muito concorreu para o advento, e posterior avanço, do

\footnotetext{
${ }^{9}$ A rigor e com brevidade, tratar-se-ia do desequilíbrio entre um forte crescimento demográfico em face de uma relativa estagnação, ou mesmo decréscimo, da produção agrícola. Em última instância, e mantidas inalteradas as curvas demográficas e de produtividade, a sociedade, fatalmente, redundaria em uma crise catastrófica cujos efeitos deletérios refreariam, ou mesmo impediriam, a retomada da prosperidade social.

${ }^{10}$ As considerações que sobre o tema têm lugar são demasiadamente amplas e complexas. Sob o baluarte do objetivo corrente, faço-me excessiva simplista ao lidar com o tópico. Assim procedo, haja vista meu interesse em estreitar o acareamento entre alguns pontos da Escola da Califórnia com outros da herança braudeliana.
} 
referido comércio, conquanto o Estado chinês impôs óbice ao mesmo processo. ${ }^{11}$ Nessa esteira, as considerações de Pomeranz são elucidativas.

De acordo com o autor, a dinastia Qing não se valeu da coerção militar para promover seu comércio ultramarino, estando, dessa forma, à margem das taxas anormalmente altas de lucratividade. Em detalhe, esse Estado teria sido indiferente, ou até mesmo hostil, àqueles que se estabeleciam no ultramar, cuja atuação "poderia ter sido crucial para um posto comercial ou um império colonial”. Perante à Europa, a política chinesa pouco fomentou a prática monopolista, ${ }^{12}$ além de ter dirimido o exercício do Estado como tomador de crédito e vendedor de cargos públicos. Esse Estado "foi, então, menos favorável ao crescimento de um esforço capitalista do que o foram os competitivos Estados da Europa Moderna". A política financeira estatal que, na Europa, "não apenas promoveu grandes lucros para muitos capitalistas europeus ricos, mas também serviu como um laboratório para novas instituições financeiras", no caso chinês ofereceu "muito menos oportunidades para os grandes mercadores chineses". Na condição de hipótese de estudo, conclui o autor: "talvez as concessões que as maiores firmas europeias receberam a partir de seu envolvimento com os Estados tenham valido muito à pena face as interferências que sofreram", de modo que "a política econômica europeia conduziu mais à acumulação capitalista do que a chinesa" (POMERANZ, 2000, p. 173).

Ainda no que toca ao comércio de longa distância, Pomeranz (2000, p. 200-204) não nega que mercadores chineses tenham se estabelecido no sudeste asiático. Contudo, observa que o fizeram sem o suporte do Estado, o que impediu que a região se tornasse para a China o que o Novo Mundo significou para a Europa Ocidental. Em seu

\footnotetext{
${ }^{11}$ Apenas para situar o leitor no debate, para Fairbank (2006), as causas do declínio chinês no século XIX podem ser explicadas pelas razões a seguir: 1) a considerável oferta de mão de obra erigiu barreiras ao implemento de medidas orientadas para o acréscimo da produtividade, fato esse que impôs fortes obstáculos a uma possível alteração nos meios de produção em termos manufatureiros, tal como aquela vivenciada pela Inglaterra; 2) uma elite comercial fraca, cujo crescimento não contou com o apoio estatal; 3) uma nobreza amparada por terra e pelo Estado; 4) o desprezo do confucionismo pelo lucro, pelo empreendimento privado e pelo individualismo. Por seu turno, Paul Kennedy (1988) defende que a China, refém de seu próprio sucesso na prematura unificação territorial e política, arrefeceu as disputas entre suas províncias, sem o que poderia ter engendrado progressos militares, tecnológicos e comerciais. De resto, o autor evoca a desconfiança da aristocracia estatal confuciana com o comércio e com a manufatura como fonte de desestímulo ao progresso tecnológico em vários setores, dentre os quais o naval. Já a Europa soube se valer das disputas entre seus Estados, culminando na chamada "espiral ascendente de crescimento econômico e eficiência militar", cuja resultante estabeleceu o domínio europeu sobre o globo (KENNEDY, 1988).

${ }^{12}$ Houve monopólio no sal, mas não no tabaco, no açúcar, no álcool e em outros pequenos luxos populares que tanto lucro os governantes estatais e os mercadores por eles favorecidos (Pomeranz, 2000, p. 173).
} 
entender, a burocracia não objetivava estender suporte militar e político quer para os mercadores interessados em operar naquelas paragens, quer para emigrantes lá residentes. Esse fastio conferiu condições aos holandeses e aos espanhóis tanto para imporem óbices às largas comunidades de mercadores chineses em adquirir terras em Manila e na Batávia quanto para expulsá-los ou incentivar nativos a fazê-lo. Mediante condições tão adversas quanto essas, os mercadores, que teimavam em operar por aquelas bandas, mantinham sempre seus ativos líquidos. As resultantes então advindas explicam alguns dos motivos de o comércio ultramarino chinês ter se desenvolvido "de forma bastante diferentes daquele capitalismo ligado ao Estado" que, por tão longo tempo, favoreceu e protegeu as companhias de comércio europeias.

Em certa medida, a inapetência do Estado chinês em proporcionar condições ótimas para o comércio de longa distância, para o aferimento de vultosos lucros e para o estabelecimento de um projeto de império ultramarino calcado, dentre outros grupos sociais, em uma comunidade mercantil forte, encaminha a cumplicidade explicativa das duas propostas em tela, ou seja, tanto Braudel quanto Pomeranz não perdem de vista o cariz da dinastia Qing. Ainda nesse âmbito, o da correlação entre políticas estatais e comportamento do sistema comercial, tem-se outro nó de ligação entre os autores. Segundo Braudel (1996a), um forte incômodo para o mercador está relacionado com a "regulação precisa e pesada do mercado público geral". Com o intuito de superá-la, floresceu o "sistema de mercado privado", que seria "a resposta visível em toda a parte às exigências de uma economia de mercado que cresce, se acelera, se transforma, solicita o espírito empreendedor em todos os níveis" (BRAUDEL, 1996a, p. 363, grifo do autor). Mais de perto, a presença desse mercado privado compõe uma essência basilar ao nascente sistema capitalista:

Se todas as mercadorias devem obrigatoriamente confluir para o mercado público, este se torna instrumento de um confronto concreto entre a oferta e a procura, e a tarifação instável do mercado passa a ser apenas a expressão desse confronto e uma maneira de preservar a concorrência real tanto entre os produtores como entre revendedores. $\mathrm{O}$ aumento das trocas condenava inevitavelmente, num prazo mais ou menos longo, essa regulamentação manietante até o absurdo. Mas as negociações diretas do mercado privado não visam apenas à eficácia; tendem também a eliminar a concorrência, a promover na base um microcapitalismo que segue, substancialmente, as mesmas vias que o capitalismo das atividades superiores da troca. O procedimento mais habitual desses microcapitalistas que constroem, às vezes depressa, pequenas fortunas é, na realidade, o de se colocarem fora dos preços do mercado, graças aos adiantamentos de dinheiro e aos jogos elementares do crédito: comprar o trigo antes da colheita, a lã antes da tosquia, o vinho antes da vindima, dirigir os preços utilizando a armazenagem dos gêneros alimentícios e, finalmente, manter o produtor à sua mercê (BRAUDEL, 1996a, p. 364). 
Infere-se, pois, a prática monopolista a nível reduzido, fora dos grandes circuitos mercantis de longa distância. À guisa de similaridade, reproduz-se a mesma lógica do comércio a grosso, gerando costumes "microcapitalistas" que, adstritos à praxe capitalista dos superlucros, comporiam a teia mais ampla do sistema como um todo. Em que pese os supostos benefícios para a vida econômica coeva, seus corolários resultam, claramente, lesivos ao conjunto social, impondo, dessa forma, as práticas de regulamentação levadas à cabo pelas monarquias da época. ${ }^{13}$ No que tange à China, Pomeranz (2000, p. 86-87) sustenta que o Estado Qing esteve sempre vigilante na busca por salvaguardar a pluralidade de compradores e de vendedores atuantes no mercado de modo a mitigar os efeitos deletérios do mercado privado que, continuamente, endividava os camponeses na Europa. De passagem, quanto mais por garantir condições justas de atuação do camponês no mercado do que por excesso de zelo burocrático, esse teria sido, até 1850, o principal escopo do sistema de concessão de licença para mercadores e corretores na China - raramente um camponês perdia a habilidade de escolher para quem queria vender sua produção. Ipso facto, os camponeses sinos gozavam de muito mais liberdade do que seus pares europeus para se engajarem na produção comercial de artesanato, visto que os compradores competiam entre si para adquiri-la. Desse cenário, não decorreu a presença de um mercado privado, mas sim, condições amplamente favoráveis ao camponês, fomentando, em adição a várias outras características da sociedade chinesa, um nível de vida muito superior ao de seu congênere europeu. ${ }^{14}$

Com fins de ilustração, Peer Vries (2015, p. 22-26) entende que as recentes interpretações sobre as políticas do governo central chinês podem, no máximo, ser definidas como uma espécie de paternalismo agrário. Para ele, a economia doméstica chinesa com seus vários pequenos produtores e consumidores, seus vários mercados e seu substancial nível de integração operava, basicamente, em linhas definidas por Adam Smith. Dito de outra forma, no decurso do século XVIII, a China pode ser considerada uma economia de mercado comercializada - ou, nos termos de Smith, uma "sociedade

\footnotetext{
${ }^{13}$ Para um excelente estudo acerca dessa lógica de funcionamento, conferir Thompson (1998).

14 Apenas como exemplificação, a maior parte da população na Ásia tinha cesso ao algodão que, na Europa, estava restrito aos mais ricos. É igualmente interessante informar que a expectativa de vida em algumas áreas na Ásia era bem superior à média aferida na Europa Ocidental, até porque, a renda média no Japão, na China e em outras localidades asiáticas era igual, e não raro maior, do que da Europa até finais do século XVIII. Em detalhe, a distribuição de renda na China da dinastia Qing (1644-1912) e no Japão dos Tokugawa (1603-1868) foi extremamente menos desigual do que na Europa Ocidental, em particular na Grã-Bretanha, no final do século XVIII (Pomeranz, 2000, p. 36-50).
} 
comercial" -, com um governo somente interferindo no mecanismo de mercado quando houvesse temor de que o padrão de vida das pessoas restasse em risco. Consoante a atual historiografia chinesa, e em termos de vida econômica, o governo não era despótico, mas, antes, beneficente e muito eficiente - tratar-se-ia de um Estado com ingerência em determinados aspectos da vida pública, sendo que, na esfera agrícola, a segurança e a riqueza do povo desfrutavam de primazia sobre a liberdade individual.

No geral, o sistema administrativo chinês seria superior ao europeu, pois seus funcionários nem eram membros da nobreza de nascimento, sem o perfil adequado para a função, e nem ingressavam nos quadros da governança via compra de cargo ou recebimento do mesmo em herança, muito menos absorvia, em seus quadros, indivíduos de procedência local que exerciam função pública sem remuneração ou qualificação. Por fim, avancemos para os autores que estudaram o processo da Grande Convergência. Adiantando, três são os pontos de contato entre esses autores e Braudel, a saber: a adoção da Longa Duração como arcabouço metodológico de análise, a identificação dos primórdios do sistema capitalista em finais do período medievo e a confluência da noção de centro e de periferia na abordagem da economia mundial.

Segundo Grinin e Korotayev (2015), a Grande Divergência e a posterior Convergência são fases de um mesmo processo, a saber: o processo de modernização do sistema econômico mundial, ${ }^{15}$ cujo albor é passível de ser datado entre os séculos VI e XI, momento em que o nível de invenções e descobertas tecnológicas na Ásia superava em muito aquele observado na Europa. Em resposta, essa região deu vez a um longo processo de aprimoramento tecnológico orientado para aumentar a produtividade. Somada à maior disponibilidade energética europeia em face de a asiática, a Europa deu vida a um movimento de importação, e posterior aperfeiçoamento, de tecnologia oriunda da Ásia - para os autores, nesse período, a Europa, então importadora de produtos manufaturados e de luxo da Ásia, poderia ser considerada periferia do continente asiático; quiçá essa constatação causasse certa inquietação a Braudel! A partir do século XV, a Europa teria efetivamente superado a China em termos tecnológicos. Consoante Grimin e Korotayev, "o período entre 1100 e 1450 pode ser visto como um período preparatório para a Revolução Industrial com uma manifestação

\footnotetext{
${ }^{15}$ Nas palavras dos autores: "A Grande Divergência não é apenas um processo de crescimento das diferenças nos níveis de desenvolvimento do Oeste e do Resto, mas também um processo de emergência de um novo tipo de sistema econômico global no qual as economias de vários países foram incorporadas em um único sistema econômico mundial (mas com papeis muito diferentes)". Similarmente, A Grande Convergência está alterando o sistema mundial e o papel das nações nele atuantes devido às novas oportunidades da divisão global do trabalho (GRININ; KOROTAYEV, 2015, p. 7).
} 
inicial bastante vívida de formas de produção e de relações capitalistas" (GRININ; KOROTAYEV, 2015, p. 17-21).

Avançando e reforçando o recorte da Longa Duração na análise dos autores, ${ }^{16} \mathrm{o}$ intervalo compreendido entre 1450 e 1750 encerra tanto uma convergência quanto uma divergência entre Ásia e Europa à luz do processo de invenção tecnológica e do avanço produtivo aludidos anteriormente. Nessa esteira, denominam o período como catching up divergence, ${ }^{17}$ cujas características me interessam, aqui, as descobertas ultramarinas, pois esse é um tema caro a Braudel, visto que evoca o comércio de longa distância e a possibilidade de aferir os superlucros próprios desse nível do sistema capitalista mercantil. Segundo os autores, os corolários mais destacados desse processo foram: o influxo de metais preciosos para a Europa, o uso de colônias americanas para a produção agrícola em larga escala (estratégia para contornar a armadilha malthusiana) e o forte crescimento de um comércio em sua base. Para a Ásia, a consequência mais importante não foi o acréscimo mercantil junto à Europa, nem mesmo o afluxo de metal. Antes, o ponto mais significativo foi a apropriação, por África e pela Ásia, de produtos agrícolas. Em resumo, para a Europa, as descobertas foram signo de crescimento de riqueza e, para Ásia, evidenciou "a possibilidade de continuação do curso prévio para assegurar as condições para o crescimento populacional máximo" (GRININ; KOROTAYEV, 2015, p. 26).

Em boa verdade, uma vez que as engrenagens da Grande Divergência foram postas em movimento, inevitavelmente, ter-se-ia a posterior Convergência por meio da globalização da economia mundial. Mais de perto, o caminho da Grande Convergência foi pavimentado pela própria Europa a partir do século XIX em duas frentes, quais sejam: primeiro, a Europa, via uso de força militar e financeira, abriu o mercado asiático para seus produtos manufaturados e, segundo, cedo percebeu que, com vistas a garantir a reiteração temporal desse recém-inaugurado mercado exportador, era imperativo aprimorar a infraestrutura desses países importadores e modernizar determinados setores dos mesmos. Isso explica, em ampla medida, o porquê de o

\footnotetext{
16 Interessante ressalvar que tanto Leonid Grinin quanto Andrey Korotayev possuem formação em História, Sociologia, Economia e Antropologia. Não me parece casual a escolha da Longa Duração como estrutura de análise pois, consoante Braudel e conforme já pontuando no corrente artigo, este seria o nível privilegiado da interdisciplinaridade - notadamente entre História, Sociologia e Economia.

${ }^{17} \mathrm{O}$ termo denota o período de aproximação do momento em que A Grande Divergência, efetivamente, teria vez com o albor da Revolução Industrial. Assim sendo, optei por não traduzir o termo para o português.
} 
[...] processo de abertura e expansão desses mercados quase imediatamente requereu a exportação de capital, no geral, e de massivos investimentos em infraestrutura, no particular, assim como a expansão da produção de matériaprima nos países da periferia do sistema mundial [...] No geral, isso contribuiu significativamente para o desenvolvimento da indústria e da economia locais e para o crescimento da consciência nacional. Nas décadas recentes, o esforço ocidental pela livre circulação de seu capital e de seus produtos eventualmente levou a uma nova e mais poderosa onda de globalização econômica, uma onda através da qual a desindustrialização do ocidente e a industrialização do oriente se iniciou (GRININ; KOROTAYEV, 2015, p. 6-7).

Percebe-se, então, que, mesmo por caminhos deveras dessemelhantes aos percorridos por Braudel, e ao abrigo dos três pontos de contato assinalados anteriormente, a análise de Grinin e de Korotayev, indubitavelmente, foi influenciada pela orientação braudeliana de pesquisa. Porém, o mais interessante consiste em observar como os autores retrocederam em séculos para explicar, não necessariamente A Grande Divergência em si, mas o processo que resultou na Grande Convergência percebida desde a década de 1980. Ao fazê-lo, concluíram se tratar de um único movimento de longuíssima duração, cujo albor data do período compreendido entre os séculos VI e XI e perdura até os dias de hoje. Nesse transcurso, pautaram três momentos de alteração, mesmo que lentas, da sua estrutura, a saber: 1100 até 1450,1450 até 1750 e daí até os dias atuais. Tendo em conta que, na Longa Duração, a paisagem causa a miragem da imutabilidade e da estabilidade, impõe-se uma análise muito criteriosa para identificar os poucos momentos de alteração, de mudança, momentos de viragem na história. Nesse sentido, compreendo ser extremante auspicioso vir a público uma obra que se volta para a história em sua Longa Duração a fim de compreender como a China, egressa da queda do sistema econômico comunista soviético, pôde ter se tornado a segunda maior econômica do sistema capitalista nos dias atuais. 


\section{REFERÊNCIAS}

ARRIGHI, Giovanni; SILVER, Beverly et. al. Chaos and governance in the Modern World System. Minneapolis: University of Minnesota Press, 1999.

ARRIGHI, Giovanni. O longo século XX: dinheiro, poder e as origens do nosso tempo. Rio de Janeiro: Contraponto; UNESP, 2013 (texto original de 1994).

ARRIGHI, Giovanni. Adam Smith em Pequim: origens e fundamentos do século XXI. São Paulo: Boitempo, 2008.

BLOCH, Marc. Apologia da história ou ofício de historiador. Rio de Janeiro: Jorge Zahar Editor, 2001 (publicação original de 1949).

BRAUDEL, Fernand. A dinâmica do capitalismo. Rio de Janeiro: Rocco, 1987 (texto original de 1985).

BRAUDEL, Fernand. Civilização material, economia e capitalismo séculos XVXVIII: as estruturas do cotidiano. V. 1. São Paulo: Martins Fontes, 1995.

BRAUDEL, Fernand. Civilização material, economia e capitalismo séculos XVXVIII: os jogos das trocas. V. 2. São Paulo: Martins Fontes, 1996a.

BRAUDEL, Fernand. Civilização material, economia e capitalismo séculos XVXVIII: o tempo do mundo. V. 3. São Paulo: Martins Fontes, 1996 b.

BRAUDEL, Fernand. Escritos sobre a história. São Paulo: Perspectiva, 2005, p. 44 (texto original de 1958).

FAIRBANK, John King. China: a new history. Cambridge: Harvard University Press, 2006.

GRININ, Leonid; KOROTAYEV, Andrey. Great Divergence and Great Convergence: a global perspective. Switzerland: Springer International Publishing, 2015.

GUNDER FRANK, Andre. World accumulation. New York: Algora publishing, 1978.

HURRELL, Andrew. Os BRICS e a ordem global. Rio de Janeiro: Editora FGV, 2009.

KELMER MATHIAS, Carlos Leonardo. “Como se fossem bens de morgado': considerações teórico-metodológicas acerca do espaço econômico do ouro e do sistema econômico atlântico". In: KELMER MATHIAS, Carlos Leonardo (et. al.). Ramificações Ultramarinas: sociedades comerciais no âmbito do atlântico luso. Rio de Janeiro: FAPERJ / MAUAD X, 2017, p. 51-72.

KENNEDY, Paul. The rise and fall of the great powers. Londres: Unwin Hyman, 1988.

MEDEIROS, Carlos Aguiar de. "A economia política da internacionalização sob liderança dos EUA: Alemanha, Japão e China”. In: FIORI, José Luís (org). O poder americano. Petrópolis, RJ: Vozes, 2007, p. 139-177. 
O'BRIEN, Patrick. "Tem years of debate on the origins of the Great Divergence". In: Reviews in History, New Jersey, n. 1008, p. 1-16, nov. 2010 Disponível em: <http://www.history.ac.uk/reviews/review/1008>. Acesso em: 14 ago. 2016.

PALMA, Gabriel. "Gansos voadores e patos vulneráveis: a diferença da liderança do Japão e dos Estados Unidos no desenvolvimento do Sudeste Asiático e da América Latina”. FIORI, José Luís (org.). O poder americano. Petrópolis, RJ: Vozes, 2007, p. 393-454.

POMERANZ, Kenneth. The Great Divergence: China, Europe, and the making of Modern World Economy. Princeton University Press, 2000.

O'Neill, Jim. "Building better global economic BRICs". Global Economics. Paper N. 66, 2001. Disponível em: <http://pro790512df.pic10.websiteonline.cn/upload/buildingbetter-pdf_geEM.pdf>. Acesso em 29 set. 2017.

THOMPSON, Edward. Costumes em comuns. São Paulo: Companhia das Letras, 1998, capítulo 4 (texto original de 1971).

VIEIRA, Pedro; FILOMENO, Felipe; VIEIRA, Rosângela (orgs.). O Brasil e o capitalismo histórico: passado e presente na análise dos sistemas-mundo. São Paulo: Cultura Acadêmica Editora, 2012. Disponível em: <http://www.gpepsm.ufsc.br/html/arquivos/O_Brasil_e_o_capitalismo_historicolivro.pdf $>$

VISENTINI, Paulo (et. al.). BRICS: as potências emergentes. Petrópolis: Vozes, 2013.

VRIES, Jan de. A economia da Europa numa época de crise. Lisboa: Publicações Dom Quixote, 1991.

VRIES, Peer. State, economy and The Great Divergence: Great Britain and China, 1680s-1850s. New York: Bloomsbury Academic, 2015.

WALLERSTEIN, Immanuel. El moderno sistema mundial. Vol. 1. Madrid: Siglo XXI, 2010a (texto original de 1974).

WALLERSTEIN, Immanuel. El moderno sistema mundial. Vol. 2. Madrid: Siglo XXI, 2010b (texto original de 1980).

WALLERSTEIN, Immanuel. El moderno sistema mundial. Vol. 3. Madrid: Siglo XXI, 2010c (texto original de 1989). 